\title{
SOCIALISMO \\ Y DESCIVILIZACIÓN
}

\author{
JESÚS HUERTA DE SOTO*
}

En las páginas 80 a 83 de mi libro Socialismo, cálculo económico y función empresarial (4. a edición, Unión Editorial, Madrid 2010) explico el proceso de profundización «vertical» y extensión «horizontal» de la división del conocimiento práctico empresarial que permite (y a la vez exige) el aumento de la población, impulsa la prosperidad y bienestar general, y hace avanzar la civilización. Este proceso se basa, como allí indico: 1.ํㅡ, en la especialización de la creatividad empresarial en áreas cada vez más estrechas y específicas y con un nivel de detalle y profundización cada vez mayor; 2. ${ }^{\circ}$, en el reconocimiento del derecho de propiedad privada de los frutos del empresario creador en cada una de dichas áreas; 3. , en el libre intercambio voluntario de los frutos de la especialización de cada ser humano, intercambio siempre mutuamente beneficioso para todos los que participan en el proceso de mercado; y $4 . .^{\circ}$, en el continuo crecimiento de la población de seres humanos, que permite «ocupar» y cultivar empresarialmente un número cada vez mayor de nuevas parcelas del conocimiento empresarial creativo que enriquece a todos.

Según este análisis, todo aquello que garantice la propiedad privada de lo que es creado y aportado por cada cual al proceso productivo, que defienda la posesión pacífica de lo que cada uno concibe o descubre, y facilite (o no obstaculice) los intercambios voluntarios (siempre, mutuamente satisfactorios en el sentido de que suponen una mejoría para cada parte) genera prosperidad, aumenta la población, e impulsa el avance cuantitativo y cualitativo de la civilización. Y por el contrario, todo atentado a la posesión pacífica de los bienes y al derecho de propiedad sobre los

* Catedrático de Economía Política. Universidad Rey Juan Carlos. 
mismos, toda manipulación coactiva en el libre proceso de intercambios voluntarios, en suma, toda intervención del estado en la economía de libre mercado siempre tiene efectos indeseados, destruye la iniciativa individual, corrompe los hábitos de comportamiento moral y responsable, infantiliza y hace irresponsable a las masas, impulsa la decadencia del cuerpo social, consume la riqueza acumulada, y bloquea la expansión del género humano y de la población, así como el avance de la civilización, incrementando la pobreza por doquier.

Proponemos como ejemplo, y a modo de ilustración, el proceso de decadencia y desaparición de la civilización clásica romana, pues aunque sus hitos básicos son fácilmente extrapolables a muchas circunstancias de nuestro mundo contemporáneo, por desgracia en la actualidad la mayoría de los seres humanos han olvidado o desconocen completamente esa importante lección histórica y, como consecuencia, no se dan cuenta de los graves riesgos que hoy aquejan a nuestra civilización. En efecto, como explico con detalle en mis clases (y sintetizo en un vídeo de las mismas «sobre la caída del Imperio Romano» que para mi sorpresa en poco más de un año ya ha sido visto en internet por más de 380.000 personas), y siguiendo los estudios previos de autores como Rostovtzeff (Historia social y económica del Imperio Romano, Espasa Calpe, Madrid 1981) y Mises (La acción humana, Unión Editorial, Madrid 2011) «no fueron las invasiones bárbaras la causa y origen de la caída del Imperio Romano y del ocaso de su civilización, sino el resquebrajamiento de su interconexión económica» (ob. cit., p. 906). En concreto, Roma fue víctima de una involución en la especialización y división del proceso mercantil, al obstaculizarse e impedirse sistemáticamente desde el poder los intercambios voluntarios a precios de libre mercado en un entorno de crecimiento desbocado de las subvenciones y del gasto público consuntivo («panem et circenses») y de control estatal de los precios. La lógica de los acontecimientos es fácil de entender. Sobre todo a partir del Siglo III la compra de votos y popularidad generaliza la subvención de los alimentos («panem») con cargo al erario público a través de la «annona», así como la continua organización de los juegos públicos más fastuosos («circenses»), todo lo cual no sólo termina arruinando a 
los propietarios agrícolas de Italia sino que además hace que la población de Roma no deje de aumentar, hasta alcanzar casi el millón de habitantes (¿para qué trabajar duramente las propias tierras si sus productos no pueden venderse a precios remuneradores dado que se reparten casi gratis por el Estado en Roma?). El incentivo obvio fue abandonar el campo de Itálica y trasladarse a la ciudad a vivir a cuenta del Estado asistencial romano, cuyo coste, al devenir insoportable para el erario público, sólo pudo ser financiado reduciendo el contenido de metal precioso en la moneda (es decir, haciendo inflación). La consecuencia fue ineludible: una caída descontrolada del poder adquisitivo del dinero, es decir, una revolución al alza de los precios, frente a la cual los gobernantes reaccionaron fijándolos por decreto a sus niveles previos, e imponiendo durísimas penas a los infractores. El establecimiento de estos precios máximos generalizó la escasez (pues a los bajos precios fijados deja de ser rentable producir y buscar soluciones creativas al problema de la escasez, a la vez que artificialmente seguía incentivándose el consumo y el despilfarro). Las ciudades paulatinamente empezaron a quedar desabastecidas y la población comenzó a abandonarlas volviendo al campo para vivir mucho más pobremente en un régimen de autarquía y de mera subsistencia que sienta las bases de lo que después sería el régimen feudal.

Este proceso de descivilización, fruto de la demagógica ideología socialista, que es propia del estado del bienestar y del intervencionismo gubernamental en la economía, puede ilustrarse gráficamente de manera simplificada y a la inversa de como lo presento en la página 81 de mi ya citado libro Socialismo, cálculo económico y función empresarial, en la que explico el proceso de creciente profundización y avance de la división del trabajo (o mejor, de la especialización del conocimiento) y de la civilización.

En efecto, como se observa en el Gráfico 1, empezamos con la etapa $t_{1}$ que recoge el avanzado grado de desarrollo al que espontáneamente había llegado el proceso de mercado romano ya en el siglo I y que, como ha demostrado Peter Temin («La economía

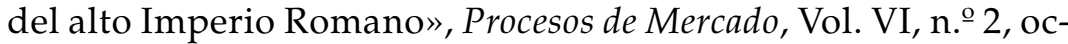
tubre 2009, pp. 165-190 y Journal of Economic Perspectives, Vol. 20, n. ${ }^{\circ}$, invierno 2006, pp. 133-151) se caracterizó por su notable 


\section{GRÁFICO 1}

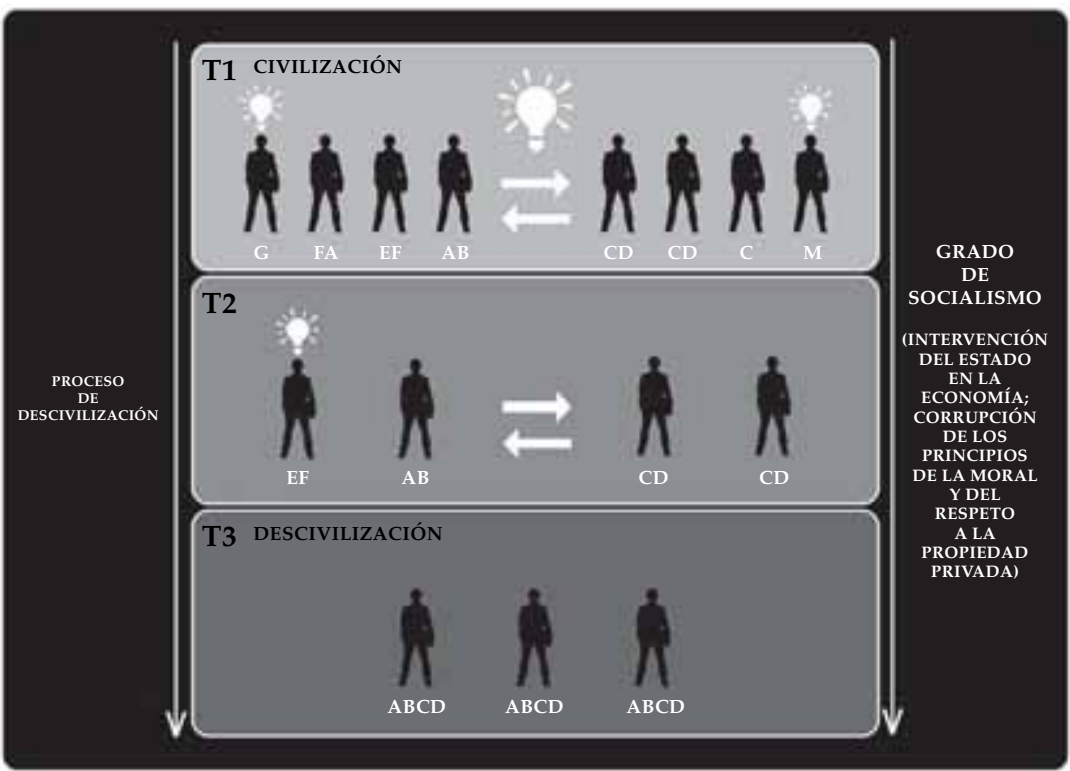

grado de respeto jurídico institucional a la propiedad privada (derecho romano), y por la especialización y generalización de los intercambios en todos los sectores y mercados de factores de producción (especialmente el laboral pues, como ha evidenciado Temin, el efecto de la esclavitud fue mucho menor de lo que hasta ahora se creía), todo lo cual hizo que la economía romana de la época alcanzara un nivel de prosperidad, desarrollo económico, urbanización y cultura que no volvería a verse en el mundo hasta bien entrado el siglo XVIII.

Las letras mayúsculas al pie de cada monigote indican los fines en los que se especializa y a los que se dedica cada actor. Este después intercambia los frutos de su esfuerzo y creatividad empresarial (representada por la bombilla que «se enciende») por los de otros actores, saliendo todos ganando después de cada intercambio. Sin embargo, cuando se incrementa la intervención del Estado en la economía (por ejemplo, con un control de precios), los intercambios se dificultan y disminuyen, por lo que los seres humanos se ven en el momento $t_{2}$ obligados a reducir el ámbito 
de su especialización, abandonando por ejemplo los fines $\mathrm{G}$ y $\mathrm{H}$ y centrándose en los fines $\mathrm{AB}, \mathrm{CD}$ y EF, todo ello con un menor grado de división del trabajo e intercambio y, por tanto, con una menor especialización que obliga a una mayor replicación y redundancia de esfuerzos, que obviamente disminuye la producción final de todo el proceso social, aumentando la pobreza.

El extremo de decadencia y contracción económica sucede en el momento $t_{3}$ en el que, ante la creciente presión intervencionista del Estado, el continuo aumento de los impuestos y la agobiante regulación, la gente, para subsistir (aunque sea a un nivel previamente inconcebible de pobreza), se ve obligada a desmontar prácticamente del todo la previa división del trabajo y el proceso de intercambios que constituye el mercado, abandonando la ciudad y volviendo al campo a pastorear y cultivar su propio alimento, a curtirse sus pieles y construir sus propios cobertizos, replicando cada uno de forma redundante los fines y actividades que, como mínimo, necesita para subsistir (los que en el Gráfico hemos llamado ABCD). La productividad, como es lógico, se reduce mucho y surgen todo tipo de carencias que disminuyen el volumen de población por falta de recursos: de esta forma el proceso de desurbanización y de descivilización ya se ha completado.

Como indica Mises «las prácticas inflacionarias, unidas a unos congelados precios máximos, paralizaron definitivamente la producción y el comercio de los artículos básicos, desintegrando toda la organización económica ... Para no morir de hambre, la gente huía de las ciudades, regresaban al campo y se dedicaban al cultivo de cereales, olivos, vides y otros productos, pero sólo para el propio consumo ... La actividad económica de las grandes urbes, el tráfico mercantil y el desenvolvimiento de las manufacturas ciudadanas se redujo de modo notable. El progreso de la división del trabajo, tanto en Italia como en las provincias del Imperio se paralizó. La estructura económica de la antigua civilización, que tan alto nivel alcanzara, retrocedió a un nivel que hoy denominaríamos feudal ... Las medidas adoptadas [por los emperadores] resultaron ineficaces puesto que no atacaban la raíz del mal. Apelar a la coacción y compulsión para invertir la tendencia hacia la desintegración social era contraproducente, ya que la descomposición precisamente traía su origen del recurso a la 
fuerza y a la coacción [por parte del estado]. Ningún romano, sin embargo, fue capaz de comprender que la decadencia del Imperio era consecuencia de la injerencia estatal en los precios y del envilecimiento de la moneda ...» (Ibidem, p. 907). Y concluye «cualquier sistema social se haya inexorablemente condenado a perecer cuando los actos humanos indispensables para que funcione normalmente son menospreciados por la moral, declarados contrarios al derecho por los códigos y perseguidos por jueces y autoridades. El Imperio romano sucumbió porque sus ciudadanos ignoraron el espíritu liberal y repudiaron la iniciativa privada. El intervencionismo económico y su corolario político, el gobierno dictatorial, descompusieron la poderosa organización de aquel Imperio, como también, en el futuro lo harán con cualquier otro régimen social» (Ibidem, p. 908, énfasis añadido).

El análisis de Mises se ha visto invariablemente confirmado no sólo en múltiples instancias históricas particulares (procesos de decadencia e involución descivilizadora, por ejemplo, en el norte y en otras partes de África; crisis acaecida en Portugal tras la «Revolución de los claveles»; el caso de la enfermedad social que afecta crónicamente a Argentina, que llegó a ser uno de los países más ricos del mundo antes de la 2. a Guerra Mundial y que hoy, en vez de recibir inmigrantes continuamente pierde población; los procesos semejantes que asolan a Venezuela y a otros regímenes populistas de Hispanoamérica, etc., etc.), sino, y sobre todo, con el experimento de socialismo real que hasta la caída del Muro de Berlín, sumió en el sufrimiento y desesperación a centenares de millones de personas. Y también hoy en día, ya en pleno mercado mundial globalizado, las fuerzas descivilizadoras del Estado del Bienestar, del sindicalismo, de la manipulación financiera y monetaria de los bancos centrales, del intervencionismo económico, de la creciente regulación y carga impositiva y del descontrol de las cuentas públicas, amenazan incluso las economías hasta ahora consideradas más prósperas (Estados Unidos y Europa) que se debaten, en plena encrucijada histórica, por desembarazarse de las fuerzas descivilizadoras de la demagogia política y del poder sindical, intentando volver a la senda del rigor monetario, del control presupuestario, de la reducción de impuestos y del desmantelamiento de la maraña de subvenciones, intervenciones y 
regulaciones que bloquean el espíritu empresarial e infantilizan y desmoralizan a las masas. De que tengan éxito en este empeño dependerá su destino futuro y, en concreto, si continúan o no encabezando como hasta ahora el avance de la civilización o, por el contrario, ante su fracaso, dejan el liderazgo de la civilización a otras sociedades que, como la chino-asiático, con gran pujanza y sin complejos desean convertirse en los principales protagonistas del nuevo mercado mundial globalizado.

Es obvio que la civilización romana no cayó como resultado de las invasiones bárbaras: más bien los bárbaros vinieron a ocupar fácilmente un proceso social que ya estaba, por causas puramente endógenas, en franca descomposición y decadencia. Mises lo expresa de la siguiente manera: «Los agresores exteriores no hicieron más que aprovechar la oportunidad que la debilidad interna del Imperio les deparaba. Desde un punto de vista militar, las hordas invasoras de los siglos IV y $\mathrm{V}$ no eran en modo alguno superiores a aquellos otros fácilmente vencidos por las legiones imperiales poco antes. Roma era lo que había cambiado; su estructura económica y social pertenecía ya al medievo» (Ibidem, p. 906).

Es más, el grado de regulación, estatismo y presión fiscal del Imperio llegó a tal nivel, que los propios ciudadanos romanos en muchas ocasiones aceptaron como mal menor someterse a los invasores bárbaros, si es que no los recibieron con los brazos completamente abiertos. Así Lactancio en su tratado Sobre las muertes de los perseguidores escrito en el año 314-315 d.C. nos dice lo siguiente: «Se llegó al extremo de que era mayor el número de los que vivían de los impuestos que los contribuyentes, hasta el punto de que al ser consumidos por la enormidad de las contribuciones los recursos de los colonos, las tierras quedaban abandonadas y los campos cultivados se transformaban en selvas ... Igualmente eran numerosos los funcionarios del fisco, magistrados y vicarios de los prefectos del pretorio cuya actividad en el orden civil era escasa, pero intensa; por el contrario, a la hora de dictar las multas y prescripciones las exacciones de todo tipo eran, no diré yo frecuentes, sino constantes, y los atropellos para llevarlas a cabo insoportables» (citado por Antonio Aparicio Pérez, La fiscalidad en la historia de España: Epoca Antigua, años 753 a.C. 
a 476 d.C., Instituto de Estudios Fiscales, Madrid 2008, p. 313). Como se ve, el paralelismo con la situación actual es muy grande en muchos aspectos, y son ya legión los tratadistas que han puesto de manifiesto que el actual nivel de subvenciones y regulaciones es una carga desmoralizante e insoportable para el cada vez más acosado sector productivo de la sociedad. De hecho, alguno de ellos, como Alberto Recarte, ha tenido la valentía de pedir que se reduzca «el número de empleados públicos, sobre todo el de los que se dedican a regular, controlar e inspeccionar, con disposiciones legales costosas y extremadamente intervencionistas, toda la actividad económica» de cuya producción dependemos todos. (El Desmoronamiento de España, Edit. La esfera de los libros, Madrid 2010, p. 126)

Y Salviano de Marsella en De Gubernatione Dei (IV, VI, 30) nos indica que "se había llegado a tal extremo de desesperación que muchos, que pertenecían a familias conocidas y habían recibido una buena educación, se veían obligados a buscar refugio entre los enemigos del pueblo romano para no ser víctimas de injustas persecuciones. Iban a los bárbaros en busca de la humanidad romana, puesto que no podían soportar entre los romanos la inhumanidad bárbara. Aunque resultaban extraños por sus costumbres e idioma a los bárbaros entre quienes se refugiaban, y aunque les chocaba su bajo nivel de vida, a pesar de todo les resultaba más fácil acostumbrarse a las costumbres bárbaras que soportar la injusta crueldad de los romanos. Se ponían al servicio de los godos o de los bagaudas y no se arrepentían, pues preferían vivir libremente con el nombre de esclavos antes que ser esclavos manteniendo solo el nombre de libres» (citado en Ibidem, pp. 314-315).

Finalmente, el historiador Osorio en sus Historias contra los paganos (Edit. Gredos, Madrid, VII, 41-7) concluye indicando que «los bárbaros, maldiciendo sus espadas, se tornaron al arado, y trataron a los romanos que habían sobrevivido, como aliados y amigos, de tal modo que entre ellos se podían encontrar romanos que preferían soportar entre los bárbaros una libertad pobre más bien que entre los romanos una continuada petición de tributos» (las cursivas son mías).

No sabemos si en el futuro la hasta ahora floreciente civilización occidental será o no sustituida por la de otros que incluso hoy 
podemos considerar como «bárbaros». Pero de lo que debemos estar seguros es de dos cosas: primero, que en la recesión más grave que ha asolado al mundo occidental desde la Gran Depresión del 29 , si no se aplican las imprescindibles medidas de desregulación, especialmente del mercado laboral, de reducción de impuestos y del intervencionismo económico, y de control del gasto público y eliminación de subvenciones, nos estamos jugando mucho más que, por ejemplo, el mero mantenimiento del euro (o para los norteamericanos, del dólar como moneda internacional) $;{ }^{1} \mathrm{y}$ segundo, que si definitivamente perdemos la batalla de la competitividad en el mercado mundial globalizado, y entramos en franca y crónica decadencia, ello se deberá, sin duda alguna, no a factores exógenos, sino a nuestros propios errores, culpas y carencias morales.

Postscriptum (tras escuchar el discurso de despedida de su Santidad el Papa Benedicto XVI el 21 de agosto de 2011 en Madrid).

A pesar de todo lo anterior no me gustaría terminar sin una nota de optimismo. Las recesiones son dolorosas y, a menudo, se utilizan como pretexto para criticar al sistema de libre mercado y para aumentar la regulación y el intervencionismo, empeorando aún más las cosas. Sin embargo, las recesiones son también las etapas en las que el cuerpo social se sanea, se descubren los errores cometidos y se sitúa a cada uno en el sitio que le corresponde. Son las etapas en las que se ponen las bases de la recuperación y se fuerza la vuelta a los principios básicos fundamentales que hacen posible el avance de la civilización. Es cierto que los desafíos son muchos, que es muy fácil dejarse llevar por el

${ }^{1}$ El proceso social no puede sobrevivir ni desarrollarse sin un marco institucional que discipline y «encorsete» a políticos, sindicatos y grupos privilegiados de interés. Aunque es seguro que nuestros gobernantes no eran conscientes de en qué se metían cuando impulsaron la creación del euro, afortunadamente en las actuales circunstancias el euro está jugando ese papel «disciplinador» al menos en los países periféricos de Europa que se ven, por primera vez en su historia, forzados a tomar medidas estructurales de liberalización económica en un entorno en el que se ha hecho evidente la inviabilidad y engaño en que se basaba el actual Estado del Bienestar. La situación en Estados Unidos es más problemática, pues aunque se constatan esporádicos esfuerzos por limitar el déficit público por parte de movimientos como el del Tea Party y otros, el carácter de reserva internacional del dólar deja mucho margen abierto a la prodigalidad de los políticos y al desenfreno del gasto. 
desánimo y que los enemigos de la libertad nos acechan por doquier. Pero no lo es menos que, frente a la cultura de la subvención, de la irresponsabilidad, de la falta de moral, y de la dependencia para todo del estado, también surge de las cenizas con gran ímpetu entre muchos jóvenes (y entre otros que ya no lo somos tanto) la cultura de la libertad empresarial, de la creatividad y de la asunción de riesgos, del comportamiento basado en principios morales y, en suma, de la madurez responsable (frente al infantilismo al que nos quieren condenar nuestros gobernantes y políticos para hacernos cada vez más serviles y dependientes). Para mi es claro quién tiene las mejores armas intelectuales y morales y, por tanto, de quién es el futuro. Por eso soy optimista. 